\title{
Building Information Modeling and Integrated Project Delivery in the Commercial Construction Industry: A Conceptual Study
}

\author{
Benedict D. Ilozor ${ }^{1}$ and David J. Kelly ${ }^{2}$ \\ ${ }^{1}$ Professor, Construction Management Programs, Eastern Michigan University, E-mail: bilozor@emich.edu. \\ ${ }^{2}$ Graduate Student, Construction Management Programs, Eastern Michigan University, E-mail: dkelly17@emich.edu \\ (corresponding author).
}

Engineering and Project Management

Received August 7, 2011; received revisions October 3, 2011; October 20, 2011; October 22, 2011; accepted October 23, 2011

Available online December 18, 2011

\begin{abstract}
In recent years, new technologies have emerged that promise to deliver efficiency, cost savings, and productivity increases to the commercial construction industry; building information modeling (BIM), and integrated project delivery (IPD) are such technologies. The literature is overwhelmingly positive with respect to the potential of BIM and/or IPD, in addition to Partnering - a less formal predecessor to IPD. This conceptual study is a critical review of the technologies, which identifies key benefits/deficiencies within the literature, synthesizes the information with comparative analysis, and conceptualizes a new framework for understanding the technologies and their interactions - the BIM/IPD Integration Model. A preliminary methodological concept for resolution of the problems uncovered is also put forth. Conclusions indicate that further study is needed to better understand the relationship between BIM and/or IPD adoption and project performance measures (e.g., cost, profit, ROI, schedule, safety, relationships, etc.) utilizing rigorous quantitative methods applied to actual project data.
\end{abstract}

Keywords: Building information modeling, integrated project delivery, partnering, commercial construction.

\section{Introduction}

Productivity in the construction industry, one of the largest industries in the United States (U.S. Department of Commerce, Bureau of Economic Analysis, 2010), has been declining since 1964 (Teicholz, 2004). The industry is often characterized as inefficient, wasteful, litigious, combative, unproductive and in need of improvement both in the U.S. (Gallaher, 2004) and abroad (Rooke et al., 2004). For example, evidence suggests that the mean speed of building construction has been declining since the erection of the Empire State Building (ESB) in 1931 (Sacks and Partouche, 2011). At just over two million square feet, the ESB was constructed in approximately 13 months (Sacks and Partouche, 2011) - an achievement that some constructors view as remarkable and simply unachievable in today's industry milieu. Many factors are potentially responsible for the apparent decline in productivity; e.g., legal setting, labor representation, government regulation, building and system complexity, contract conventions, delivery methods, technological interoperability, etc. (Gallaher, 2004; Teicholz, 2004). In recent years, two new technologies have emerged that promise to deliver efficiency, cost savings, and productivity increases to the industry: building information modeling (BIM), and integrated project delivery (IPD).
The objective of this paper is to conceptualize a new framework for understanding BIM and IPD (including Partnering), their interactions, and the resulting impact on design and construction process outcomes. The paper begins with a critical review of the literature on BIM and IPD. Key benefits and deficiencies within the literature are identified and discussed. This information is then synthesized through comparative analysis. Potential problem statements are identified which result from the analysis and a conceptual framework is put forth to further understand the technologies. The paper is concluded with the identification of future research approaches, involving rigorous quantitative methods, to measure and evaluate the effect of the technologies on the industry.

\section{Building Information Modeling}

Building information modeling (BIM) is a relatively new technology in the commercial construction industry. Eastman, Teicholz, Sacks and Liston (2008) defined BIM as an electronic replica of a project that, "contains precise geometry and relevant data needed to support the construction, fabrication, and procurement activities" (pp. 1). Furthermore, Dossick and Neff (2010) noted that "BIM makes explicit the highly interdependent nature of structure, architectural layout, and the mechanical, electrical and plumbing (MEP) systems by technologically 
coupling project participants together” (pp. 459). More plainly, BIM is a term used to describe a myriad of computer software applications that can be utilized by design and construction professionals alike to plan, layout, estimate, detail and fabricate various components of a building.

Much has been written about the apparent benefits of BIM. Eastman et al. (2008) organized the benefits of BIM utilization into four categories: pre-construction benefits (concept and feasibility), design benefits (visualization, auto correction of changes, 2-D plan generation, etc.), construction and fabrication benefits (synchronized planning, clash detection, automated fabrication, quantity survey and estimating, etc.), and post-construction benefits (management and building operations).

Automatic rule checking is an emergent topic area of BIM research (Eastman et al., 2009). In this method, the BIM model is an input to the rule checking program that automatically reviews the geometry, spatial relationships, clearances, and other dimensional and object-oriented criteria and then subsequently determines whether the proposed design complies with predefined user-generated rules. Eastman et al. (2009) noted that the potential applications of this technology are vast with automated rule checking candidates including: code compliance agencies; organizations and clients with specific building types requiring conformance to internal standards; assessment of universal concerns such as safety, structural integrity, energy consumption; and other project specific criteria established by the project team members (p. 1012). In the future, automatic rule checking could be coupled with an integrated project delivery. Elsewhere within the literature (AIA, 2007; National Association of State Facilities Administrators (NASFA) et al., 2010), this nexus of technology and process is identified as having the potential to facilitate exciting new applications for BIM, such as enhanced collaboration in accurately estimating first cost and life-cycle costs from preliminary schematic BIM models, and the use of rule-checking algorithms to automatically determine compliance of a subject design with the owner's budget, schedule, and life-cycle goals.

The fragmented and sometimes adversarial nature of the commercial construction industry has been observed to be an impediment to full realization of the benefits of BIM. Dossick and Neff (2010) conducted an ethnographic study and concluded that the competing obligations of echanical and electrical subcontractors across the landscape of scope (contractual boundaries), project (leadership), and company (resources and financial risk) serve to limit the extent of significant collaboration on projects. Furthermore, they assert that without strong leadership, the collaboration process can be reduced to simple information exchange rather than meaningful problem solving and optimization (p. 466). Proponents (AIA, 2007; NASFA et al., 2010) claim that IPD, when properly implemented, will remove some (if not all) of the impediments observed by Dossick and Neff (2010). The generalizability, reliability, and validity of these findings are somewhat suspect due to the inherent limitations of ethnography in relation to sample size.

Evidence of constructive interactions between Lean and BIM has been identified. Sacks, Koskela, Dave and Owen (2010) developed a "conceptual framework for analyzing the interaction of two transformative technologies: BIM and Lean” (p. 979). Specifically, an interaction matrix of Lean principles and BIM functionalities was developed that identified 56 interactions, all but four of which are purported to be constructive interactions suggesting that, "any company or project on a lean journey should seriously consider using BIM for enhancing the Lean outcomes. Conversely, [it is recommended that] any company or project implementing BIM should ensure that their adoption/change process is contributing to the fullest extent possible to making their processes leaner" (p. 979). This is a parallel finding to the focus of this paper, i.e., evaluating the evidence for potential synergies, and interactions between BIM and IPD.

Becerik-Gerber and Kensek (2010) surveyed a wide range of industry participants, including architects, consultants, contractors, technology providers, engineers, developers and owners to identify current research interests within the area of BIM. Their findings showed that $89 \%$ of industry respondents indicated an interest in new research on Building Information Technology and Management, while $87 \%$ indicated an interest in IPD. Future research ideas that were marked as critical included, "the concept of one virtual database versus linked information; coordination with sustainable design; rethinking of IPD as a method to promote BIM; educational ramifications, and management issues throughout the life cycle of the project" (p. 142). The concept of "rethinking of IPD as a method to promote BIM" is somewhat radical and contrary to the industry's understanding of the relationship between the two technologies as articulated by the AIA (2007), which states, "BIM provides a platform for collaboration throughout the project’s design" (p. 10). Furthermore they declare, "BIM is a tool, not a project delivery method, but IPD process methods work hand-in-hand with BIM and leverage the tool's capabilities" (p. 10). The AIA's commentary does not regard IPD as a vehicle of BIM implementation, as Becerik-Gerber and Kensek’s (2010) study suggests some industry participants may.

The use of modular construction techniques may increase as BIM becomes more prevalent within the industry ( $\mathrm{Lu}$ and Korman, 2010). The recognized advantages of modular construction include schedule improvement, enhanced quality, reduced environmental impact, on-site workforce reduction, etc. (p. 1137). Despite its apparent benefits, modular construction is not widely employed in commercial construction where its use is generally limited to correctional facilities and other types of very repetitive structures. One possible explanation for the limited use of modular techniques in commercial construction is the popularity of the traditional design-bid-build delivery model. Under this model, the modular building subcontractor would generally not be able to begin design or fabrication of their work until after completion of the construction documents, general contract bidding, and subcontract negotiation, all of which take time to complete and create potential lead-time conflicts with modular components, depending on the particulars of the project. These constraints are potentially eliminated in a BIM enabled IPD environment, where key subcontractors are involved in the process earlier (AIA, 2007; NASFA et al., 2010), creating more business opportunities for modular building fabricators. 
In order to take advantage of the potential of BIM, project management must evolve by redefining the perception of what project management is, as well as the procedures and devices utilized in project delivery (Froese, 2010). Fig. 1 features a schematic Froese's (2010) conceptual framework, which envisions a highly complex, virtual, unified, and interdependent project management approach. This framework, which depicts the interplay of processes, time, and products during a project, materialized from three recent developments: the increasing use of complex information systems that require specialized knowledge; the under-emphasis of participant interdependence by current management systems; and the increasingly common use of BIM and associated technologies as a tool in project delivery ( $p$. 531). BIM is viewed as an implement of project integration, a similar stance as the one adopted by the AIA (2007).
In response to the increase in BIM-related research, Succar (2009) developed a research framework to: systematize knowledge; advance awareness and implementation; recast BIM as an integrated solution; and connect the gap that exists between the understandings of BIM by those in academia and their counterparts in active practice (p. 358). Refer to Fig. 2 for a depiction of Succar's (2009) framework, which represents the interplay of BIM fields (players and deliverables), stages (implementation maturity) and lenses ("knowledge views”). Succar (2009) argues that IPD should be the desired endpoint of all BIM implementations, concurring with the AIA (2007) and Froese's (2010) analysis, stating that, "...the long term vision of BIM [is that of] an amalgamation of domain technologies, processes and policies” (p. 365).

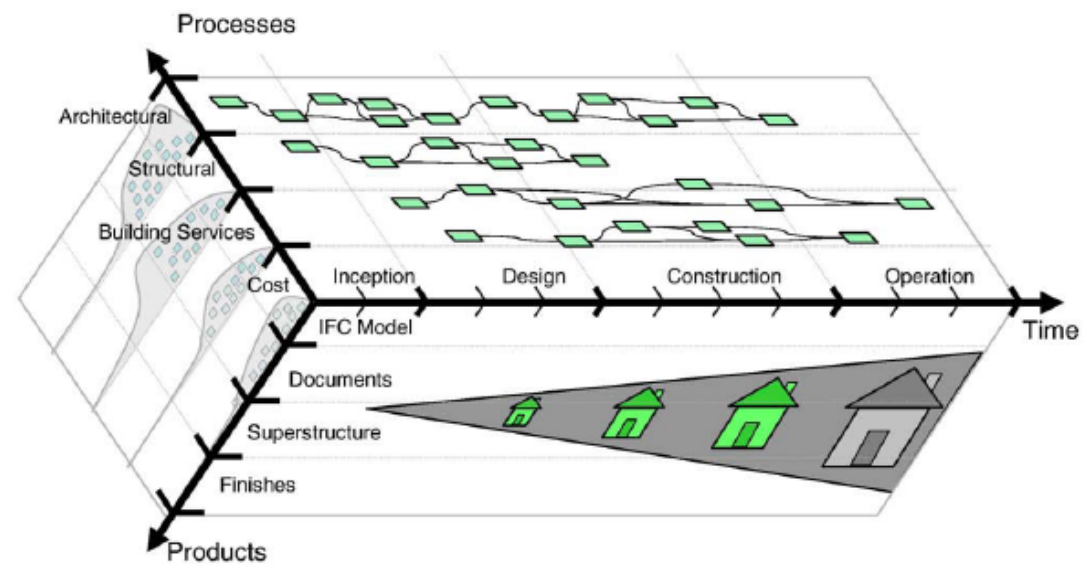

Fig.1. Schematic of the dimensions of a unified approach to project management. Reprinted from "The impact of emerging information technology on project management for construction” by T.M. Froese, 2010, Automation in Construction, 19(5), 531-538. Copyright 2009 Elsevier B.V. Reprinted with permission.

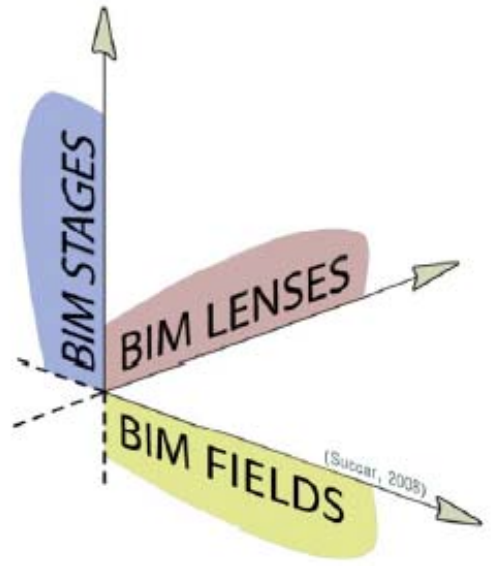

Fig.2. BIM framework: fields, stages and lenses - tri-axial model. Reprinted from "Building information modeling framework: A research and delivery foundation for industry stakeholders” by B. Succar, 2009, Automation in Construction, 18(3), 357-375. Copyright 2008 Elsevier B.V. Reprinted with permission. 
DESIGN AND CALCULATION OF RESOURCES

\begin{tabular}{l} 
DEVELOPMENT OF \\
3D MODEL AND \\
DESIGN CONTROL \\
CALCULATION \\
\hline -Vision of the project; \\
-Model (drawings and \\
descriptions).
\end{tabular}

\section{-Cost estimates of the project's alternative solutions} - Precise quantities of structural elements

-Demand for production resources (in the whole system).
ORGANIZATION AND SIMULATION OF CONSTRUCTION WORKS

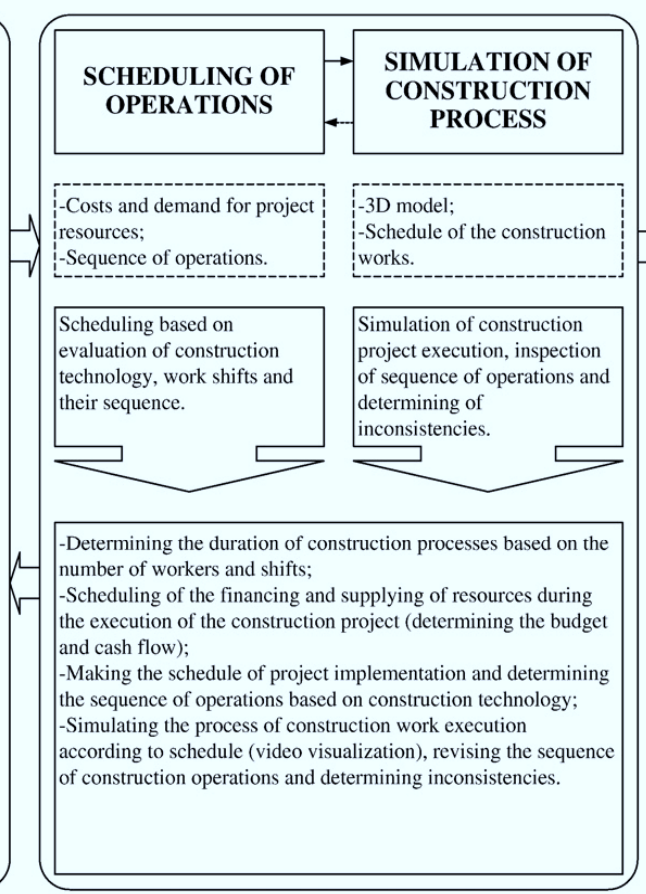

Scheduling of the entire investment construction project and its individual processes including cash flows;

-Determining the capacity (workers and equipment).

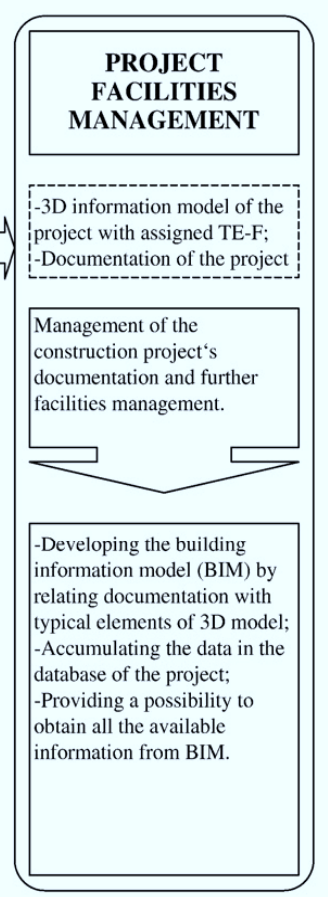

-Maintenance costs of building elements;

-Duration of the project's stages of execution.

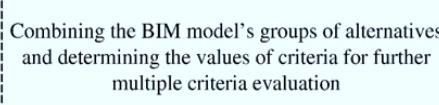
multiple criteria evaluation

\section{$\rightarrow \begin{gathered}\text { THE EVALUATION OF ALTERNATIVE USING } \\ \text { MULTIPLE } \\ \text { CRITERIA EVALUATION PROGRAM LEVI 3.0 }\end{gathered} \rightarrow$}

Choosing an economically effective alternative of the BIM model

Fig.3. Stages of project development according to the 5D concept.

Reprinted, from "The use of a virtual building design and construction model for developing an effective project concept in 5D environment” by V. Popov et al. (2010), Automation in Construction, 19(3), 357-367. Copyright 2009 Elsevier B.V. Reprinted with permission.

The 5D (3D + time + cost) project environment model developed by Popov, Juocevicius, Migilinskas, Ustinovichius and Mikalauskas (2010), categorizes the BIM-enabled project into three stages: design and calculation of resources, organization and simulation of construction works, and project facilities management. This BIM-enabled model is proposed to replace the traditional design-bid-build model that is ubiquitous throughout the industry. Refer to Fig. 3 for a representation of the model that, for all intents and purposes, is essentially what the AIA (2007) defined as the goal of integrated project delivery. The model relies heavily on BIM to enable collaboration in cost estimating, automatic document review (similar in nature to that proposed by Eastman et al. (2008)), systems analysis, value engineering, scheduling, resource allocation, site logistics, and facilities management/maintenance, among many others (p. 359). Again, BIM is envisioned as a tool for project integration.

Conversion of 2D architectural documents into working 3D models through the use of automatic graphical recognition software has been studied and advanced. Lu, Yang, Yang and Cai (2007) identified three main challenges with this process: architectural information is contained in a series of related sheets; multi-dimensional properties may be expressed in tables or charts within the documents (e.g., a footing or column schedule); and the use of abbreviations, keynotes and symbols complicates the recognition process (p. 31). Despite the challenges, Lu et al. (2007) developed algorithms that correctly identified and modeled simple architectural elements, such as doors, windows, and walls correctly with an $80 \%$ success rate. The research does not indicate whether or not the algorithms embed objectoriented data within the created model, i.e., the program may be able to scan and model a door, but does the 3D model created have the embedded characteristics of a door (e.g., hollow metal vs wood, glass lite dimensions, etc.) within the modeled object? While the widespread usefulness of this technology may be limited with respect to new construction, one application is in the conversion of outdated 2D record drawings into working 3D models that can be used as existing conditions "backgrounds" for renovation, addition, or facility management purposes.

Development of a single integrated model for projects that is capable of serving the needs of both architectural level modeler and fabrication level detailer has been identified as problematic (Eastman, 2006; Tiecholz, 2004). Current modeling technology has evolved to suit the highly specialized needs of the specific users; i.e., 
designers, engineers, architects, fabricators, contractors, estimators, etc., rather than towards an integrated oneconsolidated-model-per-project approach put forth by Becerik-Gerber and Kensik (2010). Supporters claim that the close coordination and interdependence required of IPD participants will spur them towards this end (AIA, 2007; NASFA et al., 2010). It is unlikely this will evolve quickly, given the current level of decentralization and specialization required of industry participants.

Astonishing claims of productivity increase and cost avoidance have been made within the literature. Azhar, Hein, and Sketo (2008) prepared a case study of the construction of the Hilton Aquarium in Atlanta, Georgia. Their study concluded that $\$ 600,000$ was saved in mechanical and electrical conflict avoidance on the project. However, this seemingly impressive result was based on estimates of savings for conflicts resolved during the overhead coordination process, not actual data. Additionally, the information presented indicates that the authors assumed that $75 \%$ of the conflict would have been resolved with conventional 2-D coordination processes, meaning that only $\$ 200,000$ worth of estimated conflicts were averted by the use of BIM. Lastly, the limitations on generalizability of case study method findings limit the usefulness of this work. Giel, Issa, and Olbina (2010) reported BIM ROI figures ranging from 16\% to $1654 \%$. However, Post (2009) reported results of a survey indicating an average of $70 \%$ ROI for contractors, with engineer and architect ROI figures being much lower. These conflicting findings highlight the need for a more rigorous quantitative analysis of the productivity increases, cost avoidance and ROI actually experienced by firms utilizing BIM technology.

BIM may not be a panacea to many industry problems, as the vast majority of the literature notes. Evidence suggests that it may create its own problems. Post (2011) reported on the case of a large legal settlement between insurers, designers, and contractors involving BIM on a recently completed life-sciences building. The engineers utilized BIM to design a very intricate and close-fitting overhead MEP system. However, they neglected to inform the contractor of various installation constraints. As a result, additional work was required to remedy the situation in the field. Those involved in the matter attributed the situation to poor communication and contractor naïveté with BIM, reinforcing the importance of teamwork, communication and technical expertise when utilizing the technology.

\subsection{Key Benefits of the Literature}

The literature on BIM has covered many of the important facets of the technology, including but not limited to: technical issues, industry applications, project management techniques, productivity and cost, adoption strategies, theoretical frameworks explaining its impact on and place within the industry, etc. The literature, on balance, is overwhelmingly positive regarding the future of BIM and the many benefits it has already brought to the business. Refer to Table 1 for a visual representation of the major themes presented within the literature.

Table 1. Interaction Table - BIM literature

\begin{tabular}{|c|c|c|c|c|c|c|c|c|c|c|c|c|}
\hline \multirow[b]{2}{*}{ Author(s) } & \multirow[b]{2}{*}{ 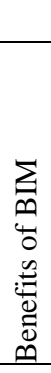 } & \multicolumn{10}{|c|}{ Topic, theme, or idea furthered } & \multirow[b]{2}{*}{ 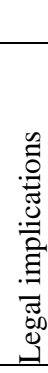 } \\
\hline & & 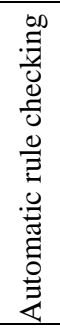 & 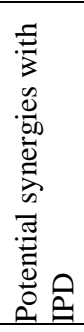 & 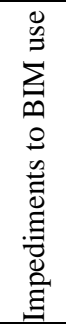 & 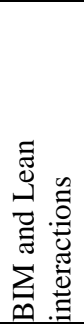 & 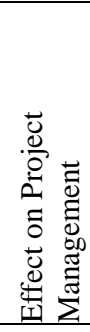 & 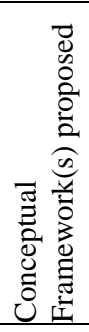 & 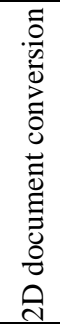 & 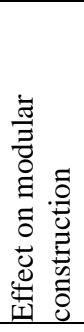 & 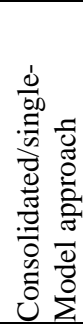 & 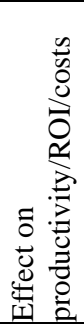 & \\
\hline Azhar et al. (2008) & $\mathrm{X}$ & & & & & & & & & & $\mathrm{X}$ & \\
\hline Becerik-Gerber and Kensek (2009) & $\mathrm{X}$ & & $\mathrm{X}$ & $\mathrm{X}$ & & & & & & & & \\
\hline Dossick and Neff (2010) & $\mathrm{X}$ & & & $\mathrm{X}$ & & $\mathrm{X}$ & & & & & & \\
\hline Eastman (2006) & $\mathrm{X}$ & & $\mathrm{X}$ & $\mathrm{X}$ & & & & & & $\mathrm{X}$ & & \\
\hline Eastman et al. (2008) & $\mathrm{X}$ & & $\mathrm{X}$ & & & & & & $\mathrm{X}$ & & & \\
\hline Eastman et al. (2009) & $\mathrm{X}$ & $\mathrm{X}$ & $\mathrm{X}$ & & & & & & & & & \\
\hline Froese (2010) & $\mathrm{X}$ & & $\mathrm{X}$ & $\mathrm{X}$ & & $\mathrm{X}$ & $\mathrm{X}$ & & & & & \\
\hline Lu et al. (2007) & $\mathrm{X}$ & $\mathrm{X}$ & & & & & & $\mathrm{X}$ & & & & \\
\hline Giel et al. (2010) & $\mathrm{X}$ & & & & & & & & & & $\mathrm{X}$ & \\
\hline Lu and Korman (2010) & $\mathrm{X}$ & & $\mathrm{X}$ & & & & & & $\mathrm{X}$ & & & \\
\hline Popov et al. (2010) & $\mathrm{X}$ & & $\mathrm{X}$ & & & & $\mathrm{X}$ & & & & & \\
\hline Post (2011) & & & & & & & & & & & & $\mathrm{X}$ \\
\hline Sacks et al. (2010) & $\mathrm{X}$ & & & & $\mathrm{X}$ & & & & & & & \\
\hline
\end{tabular}

Note: Visual representation of the major themes presented within the literature review. All but one paper deals with the benefits of BIM, typically in the introductory pages. 


\subsection{Key Deficiencies within the Literature}

There is a lack of thorough quantitative analysis and rigorous independent verification of the many qualitative assertions made within the literature with respect to BIM's potential positive impact on productivity, cost, schedule, quality, etc. While two papers did focus primarily on productivity, ROI, and cost benefits (Azhar et al., 2008; Giel, 2010), there is a gap with respect to meticulous verification of the purported benefits of BIM adoption. For example, studies reporting the actual labor hours expended per square-foot (or other quantifiable metric) by contractors on comparable projects, both before and after BIM adoption, were not found.

Safety was not mentioned at length in the literature sampled. This is startling because of fundamental importance of this topic to contractors and the potential to improve safety loss rates with more off-site prefabrication activities enabled by BIM.

Lastly, the sociological effects of BIM technology on the industry have not been explored extensively within the literature.

\section{Integrated Project Delivery}

Integrated Project Delivery (IPD) is a method of managing large-scale construction and development projects. It is formal collaboration that occurs throughout the design, planning, and execution phases of a project. The goals of IPD are to assist owners, designers and constructors in reducing waste, cutting costs, and improving productivity (AIA, 2007).

The American Institute of Architects (AIA, 2007) defines Integrated Project Delivery (IPD) as, “... a project delivery approach that integrates people, systems, business structures and practices into a process that collaboratively harnesses the talents and insights of all participants to optimize project results, increase value to the owner, reduce waste, and maximize efficiency through all phases of design, fabrication, and construction" (AIA, 2007).

Specifically, IPD consists of a multidisciplinary team of design and construction professionals assembled to complete a project, who are bound together by alternative forms of agreement that require team members to share risk and reward, contribute equally, and employ alternative processes and technologies, all in support of achieving reduced cost, time, loss and waste metrics.

The NASFA et al. (2010) jointly define IPD in a similar fashion as AIA (2007). However, they note that the emergence of IPD can be viewed as the result of the union of three recent technical and organizational developments within the industry: BIM, Lean, and Sustainability (NASFA et al., 2010). Additionally, they characterize BIM as, "technology that supports the delivery of projects in a more collaborative and integrative way" (p. 9) - a somewhat rigid definition that clearly subordinates BIM to the ends of IPD. As for sustainability, they cite the work of Molenaar, Sobin, Gransberg,
McCuen, Korkmaz and Horman (2009) supporting early constructor involvement as significant in achieving the owners' sustainability goals.

Project participants are actors reciting scripts that originate from within the social and contractual structure of the project environment. As these scripts are enacted, the structure evolves. Radical change occurs in response to outside exogenous events (e.g., the introduction of IPD or other system changes, etc.) (Barley, 1986). Giddens (1979) notes “....all social actors know a great deal about what they are doing in processes of interaction; and yet at the same time there is a great deal which they do not know about the conditions and consequences of their activities, but which nonetheless [sic] influences their course” (p. 216). That is, the actors play the part, and unknowingly change the structure they are operating within. IPD requires that team members behave differently in order for the project to succeed. The capacity of participants to adjust to new work paradigms and behaviors is critical to project success (AIA, 2007).

The most striking difference between IPD and the more traditional delivery methods (e.g., Lump Sum Design-Bid-Build (LS), Design/Build (DB), Construction Management at-risk (CMC) and Construction Management Advisor (CMa)) is the use of a single multiparty agreement where all major parties to the project execute the same agreement and share in the risk and potential rewards (Lancaster and Tobin, 2010). Both the AIA and AGC, have published model IPD agreements to facilitate IPD adoption; however, the delivery method is in its infancy and these forms are not yet widely accepted. In response, several types and forms of integrated contract agreements have been utilized for IPD projects in the past. These include the project alliance, single purpose entity, joint venture, and relational contracts (AIA, 2007). Other differences from traditional methods include team formation protocol, process, communications, technology use, and interplay. IPD is relatively new and not yet widely accepted within the industry (Kent and BecerikGerber, 2010). These differences are summarized in Table 1. The delivery method chosen will largely determine the possible risks and exposures to be encountered during construction (Ogunsanmi et al., 2011).

The centerpiece of an integrated project delivery is the project team and its members. "Building upon early contributions of individual expertise, these teams are guided by principles of trust, transparent processes, effective collaboration, open information sharing, team success tied to project success, shared risk and reward, value-based decision making, and utilization of full technological capabilities and support” (AIA, 2007, p. 2).

It follows that IPD implementation requires the project participants to follow new innovative protocols and interaction scripts resulting from the method and its embedded compensation, process, risk, teamwork, and contractual parameters. IPD requires specific behaviors among the owners, constructors, and design professionals. 
Table 2. Comparison between traditional project delivery and IPD

Traditional Project Delivery

Fragmented, assembled on "just-as

needed" or "minimum-necessary"

basis, strongly hierarchical, controlled

Linear, distinct, segregated;

knowledge gathered "just-as-

needed”; information hoarded; silos

of knowledge and expertise

Individually managed, transferred to

the greatest extent possible

Individually pursued; minimum effort for maximum return; (usually) firstcost based

Paper-based, 2-dimensional; analog
Encourage unilateral effort; allocate and transfer risk; no sharing
Compensation / Reward

Team success tied to project success; valuebased

Digitally based, virtual; Building Information Modeling (3,4 and 5 dimensional)

Characteristic

Integrated Project Delivery

An integrated team entity composed key project stakeholders, assembled early in the process, open, collaborative

Concurrent and multi-level; early contributions of knowledge and expertise; information openly shared; stakeholder trust and respect

Collectively managed, appropriately shared

Risk

Communication / technology

Encourage, foster, promote and support multilateral open sharing and collaboration; risk sharing

Note. Summary of major differences between traditional project delivery and integrated delivery. Adapted from “Integrated Project Delivery: A Guide,” by American Institute of Architects, 2007, 1. Copyright 2007 by AIA, AIA CC. Adapted with permission.

Unlike traditional delivery methods such as designbid-build, design-build and construction management, few industry practitioners have significant first-hand experience with the IPD methods. Integrated project delivery is a new and innovative delivery method for managing projects (Kent and Becerik-Gerber, 2010). In addition to the predictable technical and contractual concerns such as risk/reward, computer technology integration, and process integration, the AIA (2007) stresses the necessity of proper team formation, participant behavior, team building, and communications as critical to IPD success. Given its innovative structure and stated need for behavioral change, the introduction of IPD may represent an exogenous event that may alter actor scripts as elaborated by Barley (1986).

El-adaway (2010) found that industry and academic professionals placed great emphasis not only on the early involvement of key suppliers and manufacturers, the use of incentives, internal team-based dispute resolution, but also on the bonds developed between project team members and their conduct. Through his research, he identified ten guidelines to developing successful integrated project contracts: development of the proper project environment with solid decision making protocols; the use of a single autonomous project manager for all disciplines; the use of an outside facilitator to assist in integrated implementation and dispute resolution; integrated design process; integrated schedule development; involvement of key subcontractors and suppliers early in the process; use of open-book accounting and lump-sum fees, as opposed to \% based fees that may incentivize parties to inflate the cost; bonuses and penalties for all participating firms; a clear and unambiguous change provision clause in the event of scope growth; and a structured internal dispute resolution process that allows for a settlement of disputes between parties, without the need for outside counsel or litigation (p. 250-252). Many of these findings are consistent with recommendations put forth by the AIA (2007) and the NASFA et al. (2010).

Kent and Becerik-Gerber (2010) found similar results. Identified in their study as "trust, respect and good working relationships...” (p. 824), many of their respondents felt that IPD could not succeed without the presence of these interpersonal dynamics as a prerequisite. Surprisingly, they also found that "...monetary incentives are not the most effective [method] to foster collaboration" (p. 824), suggesting that successful IPD requires a broader cultural change among the participants.

Rooke, Seymour and Fellow (2004) examined several insidious practices embedded within the UK construction industry from the vantage point of organizational and integrated culture. They defined culture per Tylor (1913), "Culture, or civilization, taken in its wide ethnographic sense, is that complex whole which includes knowledge, belief, art, morals, law, custom, and any other capabilities and habits acquired by man as a member of society” (p.2). The common practices under evaluation in their study included: exploiting mistakes in the bidding documents, scheduling work to maximize delay impact, and proactive/reactive claims. Arguing that these tactics harm the industry, hinder competitiveness, and decrease efficiency, they proposed that while a result of economic realities, the practices have become an integral part of the culture of the UK construction industry and cannot be changed by simply removing the economic incentives (or 
dis-incentives) that spawned their pervasiveness. IPD aims to avoid all of the above-referenced harmful practices, by increasing collaboration, and among others, providing incentives for "good behavior" - a practice ironically found to be ineffective by Kent and BecerikGerber (2010).

Overcoming barriers to IPD implementation has been a recent focus of research. Ghassemi and Becerik-Gerber (2011) identified four major industry barriers: legal (appropriate contract structures), financial (shared risk and reward), cultural (trust and teamwork), and technological (interoperability between participants). The use of integrated project personnel, including the early incorporation of key subcontractors, IPD training for those new to the system, coupled with trust-building activities, appeared to help overcome some of the cultural barriers that existed. Several innovative techniques were observed to increase teamwork and trust, such as project personnel on one project all agreeing to meet face-to-face in lieu of sending emails. Another project team physically relocated all the key personnel, regardless of their employer, into the same office suite to enhance communications and build trust. These findings suggest that IPD requires behavioral and cultural modifications from traditional delivery methods.

Several standard forms of agreement have been put forth by industry associations to facilitate the use of IPD: ConsensusDocs 300: Tri-Party Collaborative Agreement (AGC); C191 Standard Form Multi-Party Agreement for Integrated Project Delivery (AIA); and C195 Standard Form Single Purpose Entity for IPD (AIA). Additionally, as with conventional delivery methods, edited versions of the standard agreement mentioned above as well as oneoff customized project-specific forms of agreement are also being utilized (AIA, 2007; NASFA et al., 2010).

It may be possible to achieve several of the benefits of IPD while continuing to utilize traditional non-integrated contract forms. Singleton and Hamzeh (2011) identified 14 IPD techniques that could be implemented on Naval Facilities Command (NAVFAC) contracts without violating pertinent provisions of the Federal Acquisition Regulations (FAR). However, some of their techniques relied on "encouraging" or "supporting" project participants to behave in certain ways, and others on "increasing ownership" of various project elements (e.g., design, schedule, etc.) While this approach may sound promising at first, it is suspect whether "encouragement" and "support" could actually affect real behavioral change, in project participants, without modification of the underlying contractual relationship.

IPD envisions a reconfiguration of the design process, shifting design decisions to earlier times in the process and redefining the industry accepted definitions. Predesign becomes Conceptualization, Schematic Design becomes Criteria Design, Design Development becomes Detailed Design, and Construction Documents become Implementation Documents (AIA, 2007). The Macleamy Curve (refer to Fig. 4) visually represents this shift in timing and altered classification of design phases. The single most important change with IPD is the forward shift of work volume to earlier stages of design.

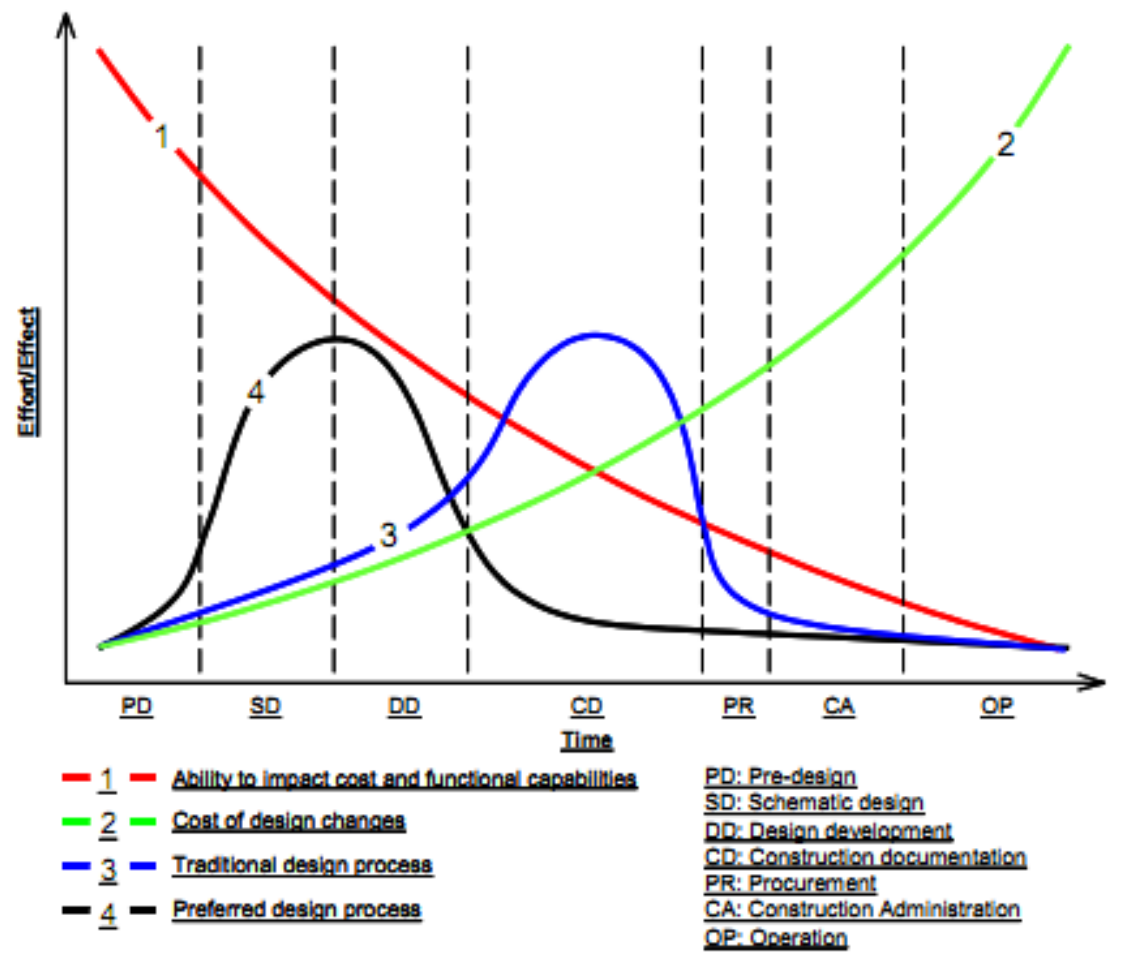

Fig.4. The Macleamy Curve (2004)

Reprinted from The Construction Users Roundtable’s “Collaboration, Integrated Information, and the Project Lifecycle in Building Design and Construction Operations” (WP-1202, August, 2004). Copyright 2004 CURT. Reprinted with permission. 
Smith, Mossman and Emmitt (2011) have identified three areas for future research with respect to IPD: Environment; Organization; and Technology. More specifically, they identify the environmental issues as those involving the "physics of project delivery and the social, cultural, behavioral context in which building practice unfolds” (p. 13); i.e., development of a solid understanding of the effects of setting and surroundings on project success. As for Organization, they envision research that would identify a variety of new methods and strategies for accomplishing the goals of IPD, essentially a new "version" of IPD. Additionally, with respect to Technology, they point directly to needed improvements required in BIM technology, specifically the need for greater, “adoption, interoperability, ownership and storage of models, and documents signing” (p.13). Lastly, they indicate that research is needed to help achieve enhanced information transfer in the fabrication phases of the projects.

\subsection{Partnering}

Many of the behaviors and attitudes that are required for IPD to succeed on a project are also required in partnering, a less formal predecessor. The United States Army Corps of Engineers (USACE) define partnering as, “A voluntary organized process by which multiple stake-holders having shared interests perform as a team to achieve mutually beneficial goals. It is based on establishing these goals early in the project lifecycle, building trusting relationships, and engaging in collaborative relationships. It requires empowering team members to solve problems at the lowest organizational level possible." (USACE, 2010)

As opposed to IPD which requires an integrated multiparty agreement, partnering is implemented after the traditional agreements are signed between contracting parties. The project principals attend a seminar to learn the basics of a partnered approach and establish a preliminary framework for trust and commitment which is intended to last the duration of the engagement. Non-binding partnering "pledges" and "charters" are the documented outcome of the seminar (Pawson and Redenbach, 2006).

While it is commonly accepted that engaging in partnering does not alter the base contract responsibilities of the parties, a recent court decision in Canada draws that conclusion into question. In EBC, Inc. v. New Brunswick (2005), a design engineer, whom after signing a partnering agreement on the project, withheld information that would have assisted the contractor in avoiding substantial additional costs in the field, was found negligent in part due to his failure to share information as promised within the partnering pledge (Pawson and Redenbach, 2006, p. 12).

Wong and Cheung (2004) studied trust in construction partnering and concluded that contractors and owners view trust and the attributes that foster it differently. Through the use of principal component factor analysis (PCFA) and varimax rotations, they found that when evaluating the concept of trust, owners are focused on, in order of importance, the following:

1. Performance - defined as an amalgamation of problem solving, competence, communication and respect;

2. Permeability - openness, alignment, financial stability, information flow;
3. System-based trust - willingness to adopt satisfactory contract terms;

4. Reputation and relational bonding - long-term relationships, and compatibility. Meanwhile, contractors were found to be focused on the following, again in order of importance:

- Performance and permeability - unity, problem solving, competence, and alignment, openness, and information flow;

- Systems-based trust;

- Relational bonding;

- Partners’ financial stability.

Surprisingly, financial stability is ranked fourth by contractors and first by owners, suggesting owners may be more skeptical of the ability of the contractor to complete the project than contractors are of owners being able to pay their bills. Not surprisingly, both groups were heavily focused on competence, ranked first for both groups indicating both groups want experienced competent counterparts with whom to conduct business.

Identifying the underlying reasons for successful partnering engagements has been explored within the literature. Chen and Chen (2007) surveyed a group of 221 industry participants from construction, design, government, and owner organizations. Using factor analysis, varimax rotations and ANOVA techniques, they ranked and then grouped 19 critical success factors into four clusters that summarized the survey data. The critical factors, in order of importance, were: collaborative team culture; long-term quality perspective; consistent objectives; and resource sharing. These results are similar to what has also been stated in the literature for IPD success, specifically the requirements identified by the AIA (2007) and NASFA et al. (2010).

The outcomes associated with partnering have also been documented. Chan, Chan and Ho (2003) surveyed 78 industry professionals about the benefits of partnering on construction projects. The top five benefits were: improved relationship amongst project participants; improved communication among participants; more responsive to the short-term emergency, changing project or business needs; reduction in dispute; and better productivity was achieved (p. 530). Similar to the research on IPD, this research measures and analyzes the perceptions and experiences of participants rather than more objective parameters, such as cost, schedule, safety, and quality metrics.

\subsection{Key Benefits of the Literature}

The literature on IPD and partnering has covered many significant issues including, but not limited to: guidelines for implementation, contracting forms and structure, differences between IPD and more conventional delivery methods, cultural and interpersonal issues; i.e., trust, teamwork, etc., required for success, best practices and overcoming barriers, process changes resulting from implementation, and synergies with BIM. The literature, on balance, is overwhelmingly positive regarding the future of IPD and the many benefits it promises to deliver to business. Refer to Table 3 for a visual representation of the major themes presented within the literature. 
Table 3. Interaction Table - IPD (and partnering) literature

\begin{tabular}{|c|c|c|c|c|c|c|c|c|c|}
\hline & \multicolumn{9}{|c|}{ Topic, theme, or idea furthered } \\
\hline Author(s) & 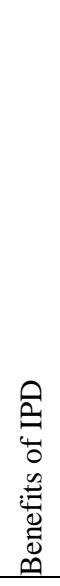 & 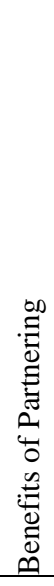 & 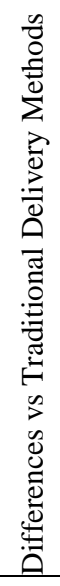 & 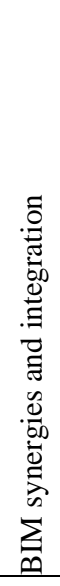 & 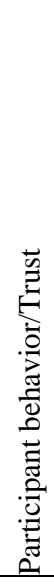 & 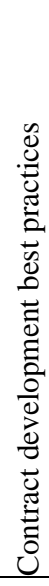 & 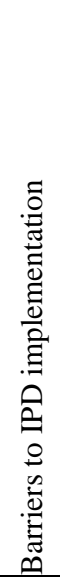 & 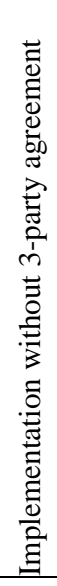 & 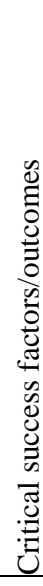 \\
\hline AIA (2007) & $\mathrm{X}$ & & $\mathrm{X}$ & $\mathrm{X}$ & $\mathrm{X}$ & $\mathrm{X}$ & & & \\
\hline Chan et al. (2003) & & $\mathrm{X}$ & & & & & & & $\mathrm{X}$ \\
\hline Chen and Chen (2010) & & $\mathrm{X}$ & & & & & & & $\mathrm{X}$ \\
\hline El-adaway (2010) & $\mathrm{X}$ & & & & & $\mathrm{X}$ & & & \\
\hline Ghassemi and Becerik-Gerber (2011) & $\mathrm{X}$ & & $\mathrm{X}$ & $\mathrm{X}$ & $\mathrm{X}$ & & $\mathrm{X}$ & & \\
\hline Kent and Becerik-Gerber (2010) & $\mathrm{X}$ & & & $\mathrm{X}$ & $\mathrm{X}$ & & & & \\
\hline Lancaster and Tobin (2010) & $\mathrm{X}$ & & & $\mathrm{X}$ & & & & & \\
\hline NASFA (2010) & $\mathrm{X}$ & & $\mathrm{X}$ & $\mathrm{X}$ & $\mathrm{X}$ & $\mathrm{X}$ & & & \\
\hline Singleton and Hamzeh (2011) & $\mathrm{X}$ & & & & & & & $\mathrm{X}$ & \\
\hline Smith, Mossman and Emmitt (2011) & $\mathrm{X}$ & & & $\mathrm{X}$ & & $\mathrm{X}$ & $\mathrm{X}$ & & \\
\hline Wong and Cheung (2004) & & $\mathrm{X}$ & & & $\mathrm{X}$ & & & & \\
\hline
\end{tabular}

Note: Visual representation of the major themes presented within the literature review. Every paper deals with the benefits of IPD(or partnering), typically in the introductory pages.

\subsection{Key Deficiencies within the Literature}

Similar to the literature on BIM, there is a lack of thorough quantitative analysis and rigorous independent verification of the many qualitative assertions made within the literature with respect to IPD's potential positive impact on productivity, cost, schedule, quality, etc.

Much of the BIM literature makes reference to potential synergies and benefits associated with coupling BIM with IPD. Likewise, every IPD article makes the point that integrated projects can greatly benefit from BIM adoption by team members. However, articles were not found that challenged or attempted to verify this relationship in any meaningful quantitative manner. Furthermore, the IPD literature does not mention partnering - its own industry predecessor whose application became widespread in the 1990's. This is especially surprising, since the behavioral and relational changes in participant behavior required to implement either method are similar in nature.
Another deficiency in the literature is an apparent lack of skepticism. Several of the articles begin with a list of citations reciting the vast potential that BIM/IPD has to affect change and solve problems in the industry. Potential to affect change does not mean that change actually happens. Astonishingly, none of the articles appears to take a step back and ask fundamental questions such as: 1.What is the evidence that the technology actually improves overall project performance? 2.How do we independently evaluate and test the technology to determine if the potential benefits are in fact real and being experienced by practitioners? 3.How do we know if the potential benefits outweigh the real costs?

Several methodologies also rely on the use of Likert scale data gathered by questionnaire. Very few studies gathered project specific performance data, most likely due to the difficulties associated with acquisition. For example, refer to Table 4 for a summary of required research data, which if gathered in adequate quantity to address sample size concerns, could lead to interesting and meaningful insights into the actual net effect of BIM/IPD on cost, productivity, schedule, etc. 
Table 4. Required research data

\begin{tabular}{|c|c|c|c|c|}
\hline Attributes & Project \# 1 & Project \# 2 & Project \# 3 & Project \# n \\
\hline Subcontractor (coded name of company) & A & B & $\mathrm{C}$ & $\ldots$ \\
\hline CM/GC (coded name of company) & $\mathrm{D}$ & $\mathrm{E}$ & $\mathrm{F}$ & $\ldots$ \\
\hline Specialty Trade & Electric & Plumbing & Fire Prot & $\ldots$ \\
\hline Architect (coded name of company) & G & $\mathrm{H}$ & I & $\ldots$ \\
\hline Engineer (coded name of company) & $\mathrm{J}$ & $\mathrm{K}$ & $\mathrm{L}$ & $\ldots$ \\
\hline $\operatorname{BIM}(\mathrm{Y} / \mathrm{N})$ & $\mathrm{N}$ & $\mathrm{Y}$ & $\mathrm{D}$ & $\ldots$ \\
\hline Schedule duration & $24 \mathrm{mos}$ & $20 \mathrm{mos}$ & $10 \mathrm{mos}$ & \\
\hline Building Type & Hospital & School & Office & $\ldots$ \\
\hline Year Built & 1990 & 2004 & 2010 & $\ldots$ \\
\hline Area (sf) & 200,000 & 150,000 & 50,000 & $\ldots$ \\
\hline \# of Floors & 4 & 2 & 3 & $\ldots$ \\
\hline Delivery method for Prime Contractor (CM, DBB, IPD, etc) & $\mathrm{CM}$ & DBB & IPD & $\ldots$ \\
\hline Delivery method subcontractor (DBB, IPD, DB, Design Assist, etc) & DBB & DBB & D-A & $\ldots$ \\
\hline Final Adjusted Contract Price (\$) & $6,000,000$ & $1,500,000$ & 150,000 & $\ldots$ \\
\hline Adjusted Labor Hour Estimate (\# of hours) & 30,000 & 7,000 & 1,000 & $\ldots$ \\
\hline Final Actual Labor Hours (\# of hours) & 31,950 & 6,850 & 850 & $\ldots$ \\
\hline Adjusted Material Estimate (\$) & $2,000,000$ & 700,000 & 35,000 & $\ldots$ \\
\hline Final Actual Material Cost (\$) & $2,200,000$ & 680,000 & 32,000 & $\ldots$ \\
\hline Lost Time Accidents (\# of) & 4 & 0 & 1 & \\
\hline
\end{tabular}

Note: An example of required data that could be gathered from industry firms and then analyzed in order to evaluate the impact of emergent technologies in a robust manner. Subcontractor, CM/GC, Architect, and Engineer would be coded data. Source: Autho

Table 4. BIM, IPD, and Partnering Comparative Analysis

\begin{tabular}{lccc}
\hline Reported Benefits for: & BIM & IPD & Partnering \\
\hline Planning and conceptualization & $\mathrm{X}$ & $\mathrm{X}$ & \\
Design and preconstruction & $\mathrm{X}$ & $\mathrm{X}$ & \\
Procurement & & $\mathrm{X}$ & \\
Fabrication & $\mathrm{X}$ & & $\mathrm{X}$ \\
Cost & $\mathrm{X}$ & $\mathrm{X}$ & $\mathrm{X}$ \\
Schedule & $\mathrm{X}$ & $\mathrm{X}$ & \\
Quality & $\mathrm{X}$ & $\mathrm{X}$ & \\
Team work and project dynamics & & $\mathrm{X}$ & \\
Building management and operations & $\mathrm{X}$ &
\end{tabular}

Note: Summarization of the reported benefits of BIM, IPD, and Partnering.

\section{BIM/IPD Integration Model}

The literature suggests that BIM and/or IPD can dramatically enhance project performance from conceptualization through building management, and ongoing operations. Refer to Table 4 for comparative summarization of the reported benefits of BIM, IPD, and Partnering.

Several research problems arising from the deficiencies identified within the literature are as follows:

1. The effect of BIM and/or IPD adoption on labor productivity needs to be better understood.

2. The effect of BIM and/or IPD adoption of the frequency of lost time accidents needs to be better understood.
3. The relationship between BIM and/or IPD adoption and construction cost needs to be better understood.

4. The effect of BIM and/or IPD adoption on contractor profits; i.e., return on investment, needs to be better understood.

In response to the benefits reported, the deficiencies noted, and the research problems stated above, a framework for understanding the impact of BIM and/or IPD on the construction process has been conceptualized - the BIM/IPD Integration Model. The above identified problems have discernable dependent and independent variables. The dependent (response) variables consist of project cost/profit, schedule, ROI, safety, productivity and relationships. The independent (explanatory) variables that may affect the response variables are the use of BIM and/or IPD. As the literature suggests, BIM and/or IPD 
may influence the conduct and outcomes of the design and construction process. The objective of subsequent studies will be to determine the effect, if any, of BIM and/or IPD on the outcomes of the design and construction process. Fig. 5 is a representation of the BIM/IPD Integration Model.

\section{Project Performance Measures}

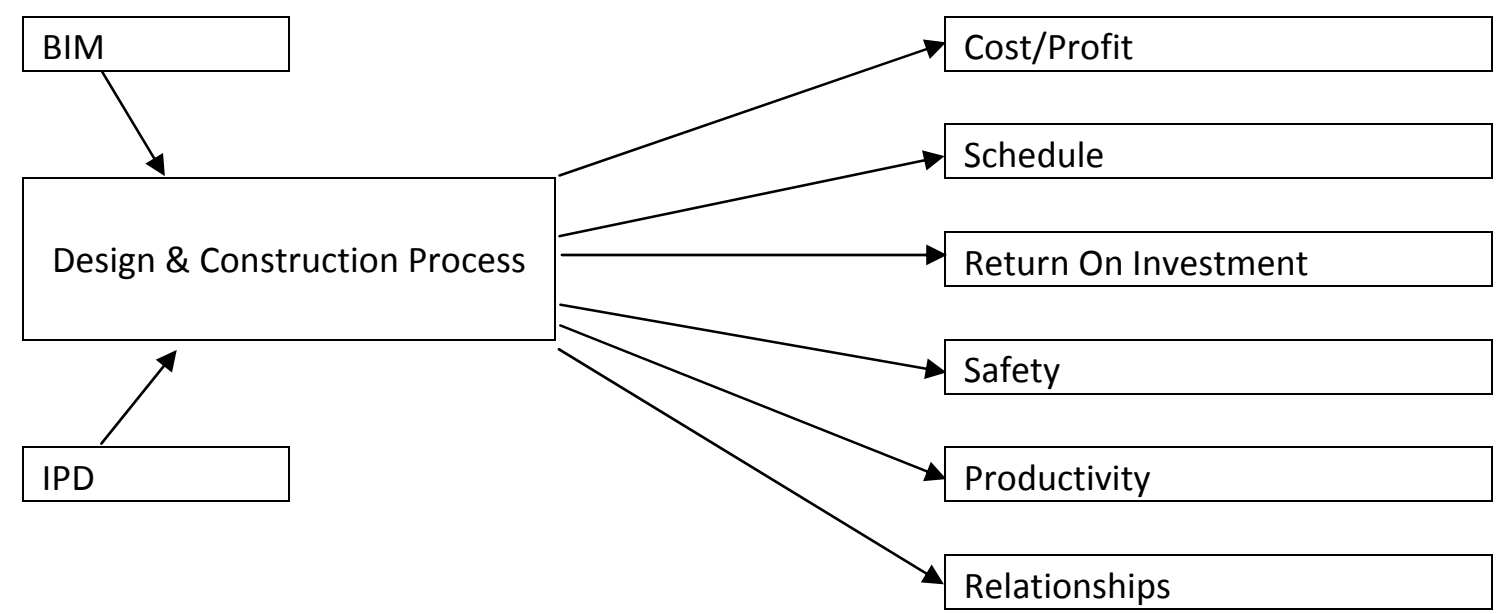

Fig. 5. A representation of the BIM/IPD Integration Model -a framework for understanding the BIM/IPD impact on the Design and Construction Process.

Potential methodologies will involve gathering data from projects that utilized BIM and/or IPD as well as those that did not. The literature, almost universally, holds that the use of BIM and/or IPD will positively impact the project performance measures. Future research will deal with the development of rigorous methodologies to quantify and then test generally accepted notions about the effect of BIM and/or IPD on project performance measures. These analyses promise to provide an interesting perspective from which to evaluate the existing literature, which is largely qualitative, case-based, and anecdotal in nature.

\section{Conclusion}

A critical analysis of the literature was conducted to develop a general understanding of the current status of BIM and IPD and the broad spectrum of sub-topic areas that research in these complimentary fields has already touched. The literature is overwhelmingly positive with respect to the positive potential of BIM and/or IPD. Several studies have documented synergies between the technologies. The majority view is that BIM is an enabling tool for IPD. However, one study indicated an opposite finding. Industry groups (e.g., AIA, AGC) have developed model agreements to facilitate the use of IPD. New approaches to BIM, including modular construction, prefabrication, document conversion, and automatic rulechecking have also been explored. BIM and IPD necessitate the forward shift of design work flow, altering traditional definitions of the design phases. The importance of trust between contracting parties is identified as being paramount in order for IPD to be successful. Conflicting findings exist regarding the ROI of BIM, highlighting the need for further study of this and related issues.

The literature was synthesized and deficiencies were identified in the realm of quantitative analysis/verification of the purported benefits of the technologies. As such, further study is recommended, including the need to better understand the relationship between BIM and/or IPD adoption and project performance (e.g., ROI, cost, schedule, safety, etc.) measures. The problems were conceptualized for future study and a preliminary methodological concept was put forth, recommending the use of data from traditional projects in addition to data from projects utilizing BIM and/or IPD. Analysis of interactions between the two technologies is also recommended.

While BIM and IPD both hold great promise to remedy some of the industry's many problems, more research utilizing rigorous quantitative methods applied to actual project data is required to properly measure and evaluate the effect of both technologies on the industry.

\section{References}

American Institute of Architects and AIA California Council (2007). Integrated Project Delivery: A Guide. Retrieved from http://www.aia.org/contractdocs/ AIAS077630 on May 1, 2011.

Azhar, S., Hein, M., and Sketo, B. (2008). Building Information Modeling: Benefits, Risks and Challenges. Proceedings, 44th Annual International Conference of the Associated Schools of Construction. Retrieved from http://ascpro.ascweb.org/chair/paper/ CPGT182002008.pdf on November 7, 2010.

Barley, S. R. (1986). Technology as an Occasion for Structuring: Evidence from Observations of CT Scanners and the Social Order of Radiology Departments. Administrative Science Quarterly, 31, 78-108.

Becerik-Gerber, B., and Kensak, K. (2010). Building Information Modeling in Architecture, Engineering, and Construction: Emerging Research Directions and Trends. Journal of Professional Issues in Engineering Education and Practice, 136(3), 139-147. doi: 10.1061/(ASCE)EI.1943-5541.0000023

Chan, A., Chan, D., and Ho, K. (2003). An Empirical Study of the Benefits of Construction Partnering in 
Hong Kong. Construction Management and Economics, 21(5), 523-533. doi: 10.1080/0144619032 000056162

Chen, W., and Chen, T. (2007). Critical Success Factors for Construction Partnering in Taiwan. International Journal of Project Management, 25, 475-485. doi:10.1016/j.ijproman.2006.12.003

Construction Users Roundtable, (2004). Collaboration, Integrated Information, and the Project Lifecycle in Building Design, Construction and Operation. (CURT Publication No. WP-1202). Retrieved from http://www.eua.com/pdf/resources/integrated_project/ Construction_Users_Round_Table.pdf on August 5, 2011.

Dossick, C. and Neff, G. (2010). Organizational Divisions in BIM-Enabled Commercial Construction. Journal of Construction Engineering and Management, 136(4), 459-467. doi:10.1061/(ASCE) C0.1943-7862.0000109

Eastman, C. A. (2006). New opportunities for IT Research in Construction. Lecture Notes in Computer Science, 4200, 163-174. doi:10.1007/11888598_18

Eastman, C.A., Teicholz, P., Sacks, R., and Liston, K. (2008). BIM handbook: a guide to building information modeling for owners, managers, designers, engineers, and contractors. Hoboken, NJ: Wiley.

Eastman, C., Lee, J., Jeong, Y., and Lee, J. (2009). Automatic Rule-Based Checking of Building Designs. Automation in Construction, 18, 1011-1033. doi:10.1016/j.autcon.2009.07.002

El-adaway, I.H. (2010). Integrated Project Delivery Case Study: Guidelines for Drafting Partnering Contract. Journal of Legal Affairs and Dispute Resolution in Engineering and Construction, 2(4), 248-254. doi:10.1061/(ASCE)LA.1943-4170.0000024

Froese, T. M. (2010). The Impact of Emerging Information Technology on Project Management for Construction. Automation in Construction, 19(5), 531-538. doi:10.1016/j.autcon.2009.11.004

Gallaher, M.P., O’Connor, A.C., Dettbarn, J.L., and Gilday, L.T. (2004). Cost Analysis of Inadequate Interoperability in the U.S. Capital Facilities Industry. Retrieved from http://www.fire.nist.gov/bfrlpubs/ build04/art022.html on July 23, 2011.

Ghassemi, R. and Becerik-Gerber, B. (2011). Transitioning to Integrated Project Delivery: Potential Barriers and Lessons Learned. Lean Construction Journal, 2011, 32-52. Retrieved from http://www.lean constructionjournal.org on May 14, 2011.

Giddens, A. (1979). Central Problems in Social Theory, Action Structure and Contradiction in Social Analysis. Berkley and Los Angeles, CA: University of California Press.

Giel, B., Issa, R., Olbina, S. (2010). Return On Investment Analysis of Building Information Modeling in Construction. Proceedings of the International Conference on Computing in Civil and Building Engineering, UK. Retrieved from http://www.engineering.nottingham.ac.uk/icccbe/proc eedings/pdf/pf77.pdf on August 5, 2011.

Kent, D.C. and Becerik-Gerber, B. (2010). Understanding Construction Industry Experience and Attitudes Toward Integrated Project Delivery, Journal of Construction Engineering and Management, 136(8), 815-825. doi:10.1061(ASCE)CO.1943-7862.0000188
Lancaster, F.D. and Tobin, J. (2010). Integrated Project Delivery: Next Generation BIM for Structural Engineering. 2010 Structural Congress, ASCE. Retrieved from ftp://ftp.eng.auburn.edu/pub/hza0002/ ASCE\%202010/data/papers/300.pdf on May 1, 2011.

Lu, T., Yang, H., Yang, R., and Cai, S. (2007). Automatic Analysis and Integration of Architectural Drawings. International, Journal on Document Analysis and Recognition, 9, 31-47. doi:10.1007/s10032-006-00296

Lu, N., and Korman, T. (2010). Implementation of Building Information Modeling in Modular Construction: Benefits and Challenges. Construction Research Congress 2010, ASCE. doi:10.1061/41109 (373) 114

Molenaar K., Sobin, N., Gransberg, D., McCuen, T., Korkmaz, S., and Horman, S. (2009). Sustainable High Performance Projects and Projects Delivery Methods, A State-of-Practice Report. Report to the Charles Pankow Foundation and the Design-Build Institute of America, September 2009, 31 pages. Retrieved from http://www.dbia.org/NR/rdonlyres/ AA033026-60BF-495B-9C9C-51353F744C71/0/Sep 2009ReportPankowDBIA.pdf on July 23, 2011.

National Association of State Facilities Administrators, Construction Owners Association of American, Association of Higher Education Facilities Officers, Associated General Contractors, and AIA (2010). Integrated Project Delivery for Public and Private Owners. Retrieved from http://www.agc.org/cs/indu stry_topics/project_delivery on July 23, 2011.

Ogunsanmi, O., Salako, and Ajayi, O. (2011). Risk Classification Model for Design and Build Projects. Journal of Engineering, Project, and Production Management, 1(1), 46-60.

Pawson, D., and Redenbach, B. (2006). Partnering Reconsidered; Court Finds Government Engineers at Fault. Canadian Consulting Engineer, 44. Document CCER000020061221e2c100008

Popov, V., Juocevicius, V., Migilimskas, D., Ustinovichius, L., and Mikakauskas, S. (2010). The Use of a Virtual Building Design and Construction Model for Developing an Effective Project Concept in 5D Environment. Automation in Construction, 19, 357-367. doi:10.1016/j.autcon.2009.12.005

Post, N. (2009, September 30). Market Study Finds Engineers Get Lowest Return from BIM. Engineering News Record. Retrieved from http://www.enr.con struction.com on July 20, 2011.

Post, N. (2011). A Cautionary Digital Tale of Virtual Design and Construction. Engineering News Record. Retrieved from http://www.enr.construction.com on July 20, 2011.

Rooke, J., Seymour, D., Fellow, R. (2004). Planning for Claims, an Ethnography of Industry Culture. Construction Management and Economics, 22, 655662. doi:10.1080/014461904200026324

Sacks, R., Koskela, L., Dave, B., and Owen, R. (2010). Interaction of Lean and Building Information Modeling in Construction, Journal of Construction Engineering and Management, 136(9), 968-980. doi:10.1061/(ASCE)CO.1943-7862.0000203

Sacks, R. and Partouche, R. (2011). Empire State Building Project: Archetype of Mass Construction, Journal of Construction Engineering and Management, 36(6), 702-710. doi:10.1061/(ASCE) CO.1943-7862.0000162 
Singleton, M.S. and Hamzeh, F. (2011). Implementing Integrated Project Delivery on Department of Navy Construction Projects, Lean Construction Journal, 2011, 17-31. Retrieved from http://www.leanconstru ctionjournal.org on May 14, 2011.

Smith, R.E., Mossman, A. and Emmitt, S. (2011). Editorial: Lean and Integrated Project Delivery Special Issue, Lean Construction Journal, 01-16. Retrieved from http://www.leanconstructionjournal. org on May 14, 2011.

Succar, B. (2009). Building Information Modeling Framework: A Research and Delivery Foundation for Industry Stakeholders. Automation in Construction, 18(3), 357. doi:10.1016/j.autcon.2008.10.003

Teicholz, P. (2004,). Labor Productivity Declines in the Construction Industry: Causes and Remedies, AEC bytes Viewpoints. Retrieved from http://www.aecb ytes.com/viewpoint/2004/issue_4.html on August 3, 2011.

Tylor, E.B. (1913). Primitive Culture, Researches into the Development of Mythology, Philosophy, Religion, Art, and Custom, London: John Murray.

U.S. Department of Commerce, Bureau of Economic Analysis (2010). Gross Output by Industry, Release Date: December 14, 2010. Retrieved from http://www.bea.gov/iTable/iTable.cfm?ReqID=5\&ste $\mathrm{p}=1$ on August 3, 2011.

United State Army Corps of Engineers (2010). Partnering: A Tool for USACE, Engineering Construction, and Operations (IWR Pamphelt 91-ADR-P-4). Retrieved from http://www.iwr.usace.army.mil/docs/iwrrep orts/91-ADR-P-4.pdf on July 23, 2011.

Wong, P. and Cheung, S. (2004). Trust in Construction Partnering: Views From Parties of the Partnering Dance. International Journal of Project Management, 22, 437-446. doi:10.1016/j.ijproman.2004.01.001

Benedict D. Ilozor, Ph.D., MNIA, FMA, Assoc. AIA, LEED AP BD+C, is a tenured full professor, contributing architecture, construction management, renewable energy and sustainability, as well as facilities planning, design, and management expertise to construction management programs in the School of Engineering Technology at Eastern Michigan University. With more than 100 publications (refereed journal papers, articles, monographs, etc.), he has received various honors and awards of excellence, and best paper prizes on innovation and sustainability in the USA, Australia, and the UK. He is an editor (Asia Pacific) for the Journal of Management Development, and he is on the editorial board of several high impact journals such as the American Society of Civil Engineers Journal of Performance of Constructed Facilities, Journal of Construction, the Journal of Engineering, Design and Technology, and the International Journal of Construction Project Management.

David J. Kelly, P.E., LEED AP BD+C, is Preconstruction Manager in the Detroit, MI, USA office of Turner Construction Company. A licensed Professional Engineer in Illinois and Michigan, David is also a part-time graduate student in the College of Technology at Eastern Michigan University, Ypsilanti, MI, USA. He serves on the Board of Directors of the Southeast Michigan Branch of the American Society of Civil Engineers and is a LEED Accredited Professional with a specialization in building design and construction. 